\title{
Axial Compressive Behavior of T-Shaped Concrete Columns with Steel Fiber Reinforced Concrete and High-Strength Stirrups
}

\author{
Linzhu Sun ${ }^{1,}$, , Dongyan Wu ${ }^{1, b}$, Junliang Zhao ${ }^{1, c}$, Fang Yang ${ }^{1, d}$ and Bo Wan ${ }^{1, e}$ \\ ${ }^{1}$ College of Civil Engineering and Architecture, Wenzhou University, Wenzhou 325035, China \\ alinzhusun@hotmail.com, bzjwzwudongyan@sina.com.cn (Corresponding author), \\ czhaojunliang@wzu.edu.cn, dyf3077@126.com, e1009835314@qq.com
}

\begin{abstract}
Keywords: T-shaped columns; high-performance concrete; high-strength stirrups; steel fiber reinforced concrete.

Abstract. Irregular-shaped columns, such as T-shaped, cross-shaped, L-shaped columns, can increase the efficiency of inner space of constructions. However, many previous studies on normal concrete irregular-shaped columns demonstrate their poor ductility, even with large amount of reinforcement. To overcome these shortcomings, this paper presents a novel irregular-shaped column with enhanced performance. It consists of high-performance fiber reinforced concrete and high-strength stirrups. To confirm the behavior of this novel irregular-shaped column, four T-shaped columns were prepared and tested under axial compression. The parameters studied include the strength of high-performance concrete, and the volume content of steel fiber. The test results show that the combination of high-strength stirrups and steel fiber reinforced concrete can improve both the axial bearing capacity and ductility of the columns.
\end{abstract}

\section{Introduction}

Irregular-shaped columns, such as T-shaped columns, cross-shaped columns, and L-shaped columns, can increase the efficiency of inner space of constructions. Many previous studies, however, generally prove that the performance of irregular-shaped columns are poor in loading carrying capacity and especially ductility, due to limited confinement effect of stirrups.

Many scholars investigated the mechanical properties and the design method of special-shaped columns worldwide, such as [1-5]. Most of the previous studies focus on the axial loading bearing capacity of irregular-shaped columns. In China, the studies on irregular-shaped columns began after 1970s, including studies on the axial loading capacity, shear capacity as well as seismic performance [6-8]. Among them, Fang [6] established equivalent uniaxial constitutive relationship for core concrete of T-shaped RC short columns. The inclusion of steel fibers in concrete can greatly increase the tensile strength, deformation capacity and crack-resistance of concrete [7]. With the technology improvement in steel manufacture, high strength steel with yielding strength larger than $1400 \mathrm{MPa}$ is already available and has been investigated by many researchers [8-10]. In this study, high strength stirrups and high performance steel fiber reinforced concrete was proposed to be used to produce irregular-shaped concrete columns with higher performance. Both the steel fiber and high strength stirrups are anticipated to increase the performance of irregular-shaped columns.

To verify the performance of irregular-shaped columns with high strength stirrups and high performance steel fiber reinforced concrete, four T-shaped columns were prepared and tested under axial compression. The strain response and load capacity of the columns were measured and analyzed with care.

\section{Experimental Program}

In this study, four columns were constructed with steel fiber reinforced concrete with different fiber content. The details of the four T-shaped columns are shown in Table 1 and Fig. 1. The column height was $1200 \mathrm{~mm}$. The dimensions of flange were $300 \mathrm{~mm} \times 100 \mathrm{~mm}$, and the dimensions of web were $200 \mathrm{~mm} \times 100 \mathrm{~mm}$. At the two ends of the columns, square cross-section with edge length of $300 \mathrm{~mm}$ was adopted to avoid end failure. 

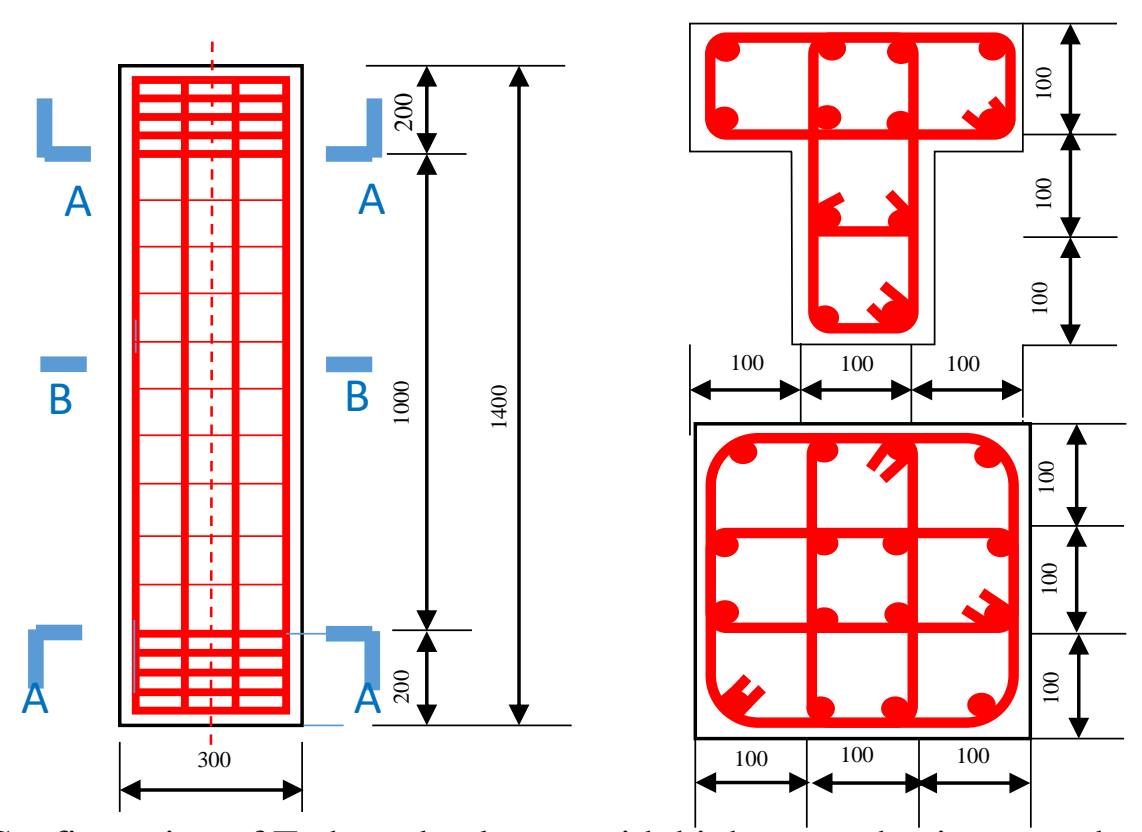

Section B-B

$12 \mathrm{~mm}$ bars

$7 \mathrm{~mm}$ stirrups

$10 \mathrm{~mm}$ cover

Section A-A

$12 \mathrm{~mm}$ bars

$7 \mathrm{~mm}$ stirrups

$10 \mathrm{~mm}$ cover

Fig. 1 Configuration of T-shaped columns with high-strength stirrups and steel fiber reinforced concrete

Table 1. Column design details

\begin{tabular}{cccccc}
\hline $\begin{array}{c}\text { Column } \\
\text { ID }\end{array}$ & $\begin{array}{c}\text { Longitudinal } \\
\text { bars }\end{array}$ & $\begin{array}{c}\text { Transverse } \\
\text { stirrups }\end{array}$ & $\begin{array}{c}\text { Tie } \\
\text { spacing } \\
{[\mathbf{m m}]}\end{array}$ & $\begin{array}{c}\text { Fiber } \\
\text { content } \boldsymbol{V}_{\boldsymbol{f}} \\
{[\boldsymbol{\%}]}\end{array}$ & $\begin{array}{c}\text { Concrete } \\
\text { compressive } \\
\text { strength (MPa) }\end{array}$ \\
\hline $100-1$ & $12 \mathrm{~mm}$ & $7 \mathrm{~mm}$ & 100 & 0 & 31.0 \\
$100-2$ & $12 \mathrm{~mm}$ & $7 \mathrm{~mm}$ & 100 & 2 & 44.9 \\
$100-3$ & $12 \mathrm{~mm}$ & $7 \mathrm{~mm}$ & 100 & 1 & 59.6 \\
$100-4$ & $12 \mathrm{~mm}$ & $7 \mathrm{~mm}$ & 100 & 2 & 66.3 \\
\hline
\end{tabular}

In all columns, there were 12 longitudinal bars with nominal diameter of $12 \mathrm{~mm}$. Normal strength steel bars were used to produce the longitudinal bars. High strength steel bars with normal diameter of $7 \mathrm{~mm}$ were used to produce the stirrups. The mechanical properties of the longitudinal bars and stirrups were shown in Table 2.

Table 2. Mechanical properties of steel reinforcement

\begin{tabular}{cccc}
\hline Bar size & $\begin{array}{c}\text { Yield strength } \boldsymbol{f}_{\boldsymbol{y}} \\
{[\mathbf{M P a}]}\end{array}$ & $\begin{array}{c}\text { Ultimate strength } \boldsymbol{f}_{\boldsymbol{u}} \\
{[\mathbf{M P a}]}\end{array}$ & $\begin{array}{c}\text { Elastic modulus } \boldsymbol{E}_{\boldsymbol{s}} \\
\text { [GPa] }\end{array}$ \\
\hline $12 \mathrm{~mm}$ & 445 & 607 & 204 \\
$7 \mathrm{~mm}$ & 1044 & 1228 & 218 \\
\hline
\end{tabular}

Steel fiber reinforced concrete were used to cast the columns. The mix proportions used to cast the specimens were listed in Table 3. The diameter and length of the straight steel fibers were $0.2 \mathrm{~mm}$ and $13 \mathrm{~mm}$ respectively, resulting in a fiber aspect ratio of 65 . The tensile strength of the fibers is 2850 $\mathrm{MPa}$ as provided by the manufacturer. The concrete compressive strength obtained from standard cylinders were shown in the last column of Table 1.

All columns were tested on a loading machine with load capacity of $10000 \mathrm{kN}$. During the test, the load was first applied at a rate of $4 \mathrm{kN} / \mathrm{s}$ until $80 \%$ of estimated load carrying capacity (estimated as $P_{\text {nom }}=0.85 f_{c} A_{c}+f_{y} A_{s}$ according to ACI 318 [11]); displacement control loading scheme was then adopted with a loading rate of $0.5 \mathrm{~mm} / \mathrm{min}$. Two LVDTs were installed on two opposite surfaces of the column to measure the deformation of the columns in the $800-\mathrm{mm}$ middle range. A photo of the test set-up is shown in Fig. 2. 
Table 3. Concrete mix proportions

\begin{tabular}{cccccccc}
\hline $\begin{array}{c}\text { Column } \\
\text { ID }\end{array}$ & $\begin{array}{c}\text { Cement } \\
\left(\mathbf{k g} / \mathbf{m}^{\mathbf{3}}\right)\end{array}$ & $\begin{array}{c}\text { Silica } \\
\text { fume } \\
\left(\mathbf{k g} / \mathbf{m}^{\mathbf{3}}\right)\end{array}$ & $\begin{array}{c}\text { Fly ash } \\
\left(\mathbf{k g} / \mathbf{m}^{\mathbf{3}}\right)\end{array}$ & $\begin{array}{c}\text { Sand } \\
\left(\mathbf{k g} / \mathbf{m}^{\mathbf{3}}\right)\end{array}$ & $\begin{array}{c}\text { Water } \\
\left(\mathbf{k g} / \mathbf{m}^{\mathbf{3}}\right)\end{array}$ & $\begin{array}{c}\text { Superplasticizer } \\
\left(\mathbf{k g} / \mathbf{m}^{\mathbf{3}}\right)\end{array}$ & $\begin{array}{c}\text { Steel } \\
\mathbf{f i b e r} \\
\left(\mathbf{k g} / \mathbf{m}^{\mathbf{3}}\right)\end{array}$ \\
\hline $100-1$ & 393.6 & 59.1 & 118.1 & 1263.5 & 256.9 & 11.42 & 0 \\
$100-2$ & 393.6 & 59.1 & 118.1 & 1263.5 & 256.9 & 11.42 & 156 \\
$100-3$ & 546.0 & 81.9 & 109.2 & 1134.3 & 269.6 & 14.74 & 78 \\
$100-4$ & 546.0 & 81.9 & 109.2 & 1134.3 & 269.6 & 14.74 & 156 \\
\hline
\end{tabular}

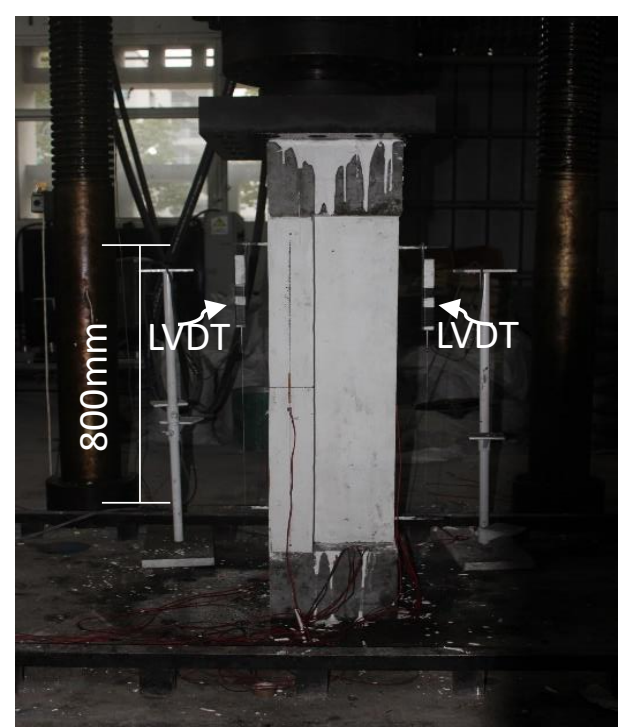

Fig. 2 Test set-up

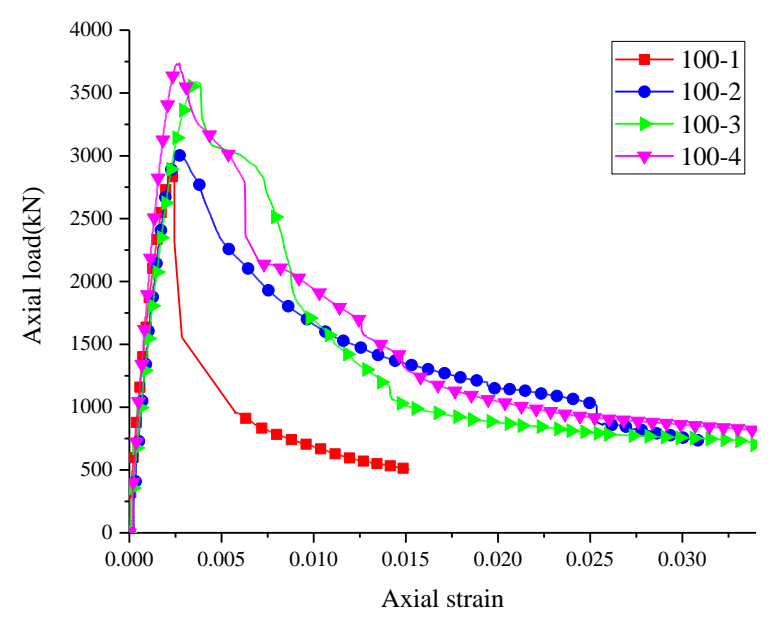

Fig. 3 Load versus axial strain curves

\section{Results and Discussion}

All columns were tested until substantial failure. The load versus axial strain curves of the four columns are shown in Fig. 3. In the figure, the longitudinal axis is the total load recorded by the loading machine and the lateral axis is the axial strain of the middle part of the column derived from the average readings of two LVDTs. Some key test results are summarized in Table 4, including the load capacity $P_{\max }$, nominal load capacity $P_{\text {nom }}$ calculated by ACI 318 [11], axial strain at peak load $\varepsilon_{c o}$, and axial strain $\varepsilon_{c 85}$ when the load has reduced to $85 \%$ of peak load.

Table 4. Key test results

\begin{tabular}{ccccc}
\hline Column ID & $\boldsymbol{P}_{\boldsymbol{m a x}}(\mathbf{k N})$ & $\boldsymbol{P}_{\text {nom }}(\mathbf{k N})$ & $\boldsymbol{\varepsilon}_{\boldsymbol{c o}}$ & $\boldsymbol{\varepsilon}_{\boldsymbol{c} \boldsymbol{8 5}}$ \\
\hline $100-1$ & 2836 & 1885 & 0.0024 & 0.0024 \\
$100-2$ & 3010 & 2460 & 0.0026 & 0.0043 \\
$100-3$ & 3587 & 3068 & 0.0036 & 0.0039 \\
$100-4$ & 3735 & 3345 & 0.0027 & 0.0043 \\
\hline
\end{tabular}

The photos of the columns after test are shown in Fig. 4. For specimens 100-1 and 100-2, a diagonal failure plane was observed in the upper middle part of the column. For specimens 100-3 and 100-4, failure also occurred in the upper middle part of the columns. However, the angle of failure surface with horizontal direction is almost zero. During the test, minor cracking of concrete was observed when the load first reached about $95 \%$ of peak load for all specimens. The cracks in specimen 100-1 developed rapidly immediately after peak load was reached, resulting in substantial spalling of concrete cover. The load capacity was suddenly reduced by about $45 \%$, indicating poor ductility in the specimen with normal concrete. For specimens 100-2 to 100-4, the cracks increase 
gradually with the decreasing of load capacity. The slope of the descending branch of load deformation curve is much smaller than specimen 100-1, due to the inclusion of steel fibers in the concrete.

Specimens 100-1 and 100-2 were cast by similar concrete. The only difference is that steel fibers were used in specimen 100-2, while not used in specimen 100-1. It can be seen from Fig. 3 and Table 4 , both the load capacity and ductility of T-shaped columns were enhanced due to the inclusion of steel fibers. The load capacity was slightly increased by about $6 \%$, while the ductility was greatly increased as shown in Fig. 3.

Specimens 100-3 and 100-4 were cast by concrete with similar mix proportion but different fiber volumetric ratio, which were $1 \%$ and $2 \%$ respectively. From Fig. 3 and Table 4, it can be seen that there is little difference between the load deformation curves of the two specimens. When the volumetric ratio of steel fiber was increased from $1 \%$ to $2 \%$, the peak load was increased by about $4 \%$ while the ductility are almost the same. As a result, $1 \%$ steel fiber is deemed appropriate for this case.

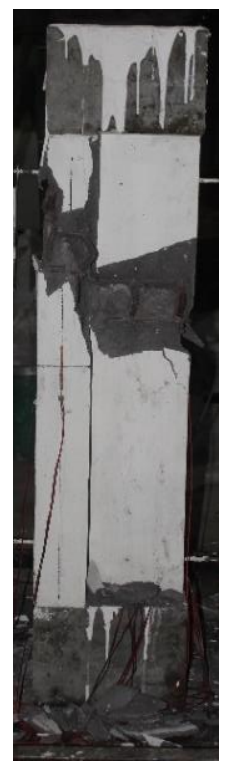

(a) $100-1$

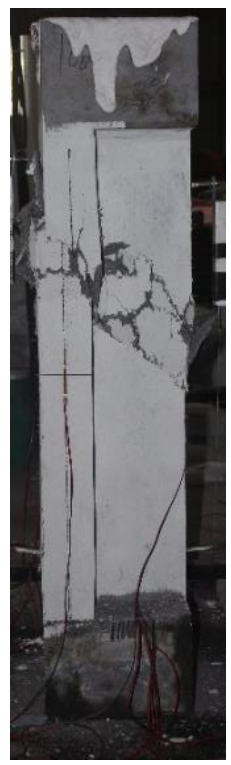

(b) $100-2$

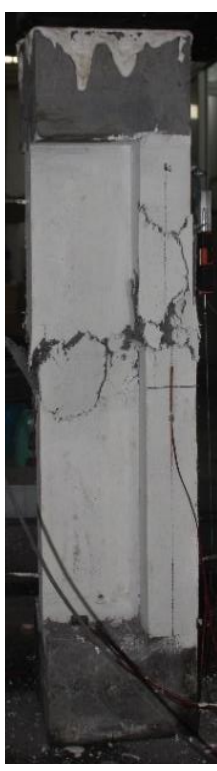

(c) $100-3$

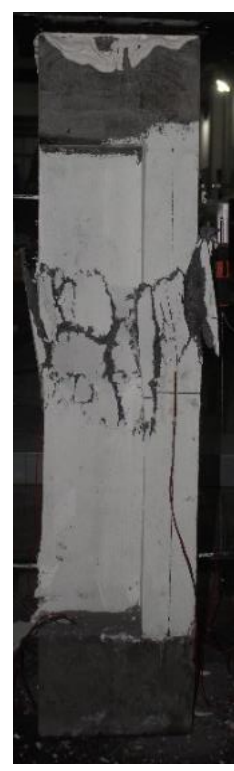

(d) $100-4$

Fig. 4 Columns after tests

\section{Summary}

In this study, a novel kind of irregular-shaped columns with steel fiber reinforced concrete and high strength stirrups was first proposed. Four T-shaped columns were prepared and tested to verify their performance. Based on the present study, both the strength and ductility of T-shaped columns were enhanced due to the usage of steel fiber reinforced concrete.

\section{Acknowledgements}

The authors are grateful for the financial support provided by the Natural Science Foundation of China (Project No. 51378398, 51508415, 51678454 and 51608392) and the Natural Science Foundation of Zhejiang Province (Project No. LQ15E080006).

\section{References}

[1] J. Marin. Design Aids for L-Shaped Reinforced Concrete Columns: ACI J PROC, Vol. 76 (1979), p. 1197.

[2] C.C.T. Hsu. Biaxially Loaded L-Shaped Reinforced Concrete Columns: J STRUT ENG, Vol. 111(1985), p. 234. 
[3] C.C.T. Hsu. Channel-Shaped Reinforced Concrete Compression Members under Biaxial Bengding: ACI STRUT J, Vol. 84(1987), p. 201.

[4] C.C.T. Hsu. T-Shaped Reinforced Concrete Members under Biaxial Bengding and Axial Compression, ACI STRUT J,Vol. 120(1989), p. 453.

[5] L.N. Ramamurthy and T.A.H. Khan. L-Shaped Column Design for Biaxial Eccentric: J STRUT ENG, Vol. 109(1983), p. 1903.

[6] F. Lin and F.J. Guo. Equivalent Uniaxial Constitutive Relationship for Core Concrete of T-Shaped RC Short Columns: J BUILD STRUT, Vol. 36(2015), p. 359.

[7] M. Yang. Strengthening and Toughening Mechanism of Steel Fiber Reinforced High-Strength Concrete and Design Method Based on Toughness (Dalian University of Technology, Dalian China 2006)

[8] F. Yang, L.Z. Sun, J.L. Zhao, D.Y. Wu and W. Li. Behavior of a Novel Circular HSC Column with Double High Strength Spirals: ADV STRUCT ENG, Vol. 18(2015), p. 1371.

[9] D. Cusson and P. Paultre. Stress-Strain Model for Confined High-Strength Concrete: J STRUT ENG, Vol. 121(1995), p. 468.

[10] H.S. Chung, K.H. Yang, Y.H. Lee and H.C. Eun. Strength and Ductility of Laterally Confined Concrete Colum: CAN J CIVIL ENG, Vol. 29(2002), p. 820.

[11] ACI Committee 318. Building Code Requirements for Structural Concrete (American Concrete Institute, Farmington Hills 2014) 